\title{
Welcome from the Editor of SURG
}

\section{Greetings,}

This year marks a milestone for undergraduate involvement in research. Along with celebrating the publication of our fifth issue, we commemorate the $20^{\text {th }}$ anniversary of SPARK, Students Promoting Awareness of Research Knowledge.

Based in the Office of Research, SPARK was a program established to encourage student involvement in written communications, and has since its inception in 1988, grown to play an important role in the research communications network at the University of Guelph.

Similarly, SURG was initiated to support our expanding curriculum of comprehensive studies, and works to cultivate the numerous opportunities made available to undergraduates interested in research.

That's reflected in this issue's content, which covers topics ranging from separating the intentions and effects of American newsprint recycling legislation on Canadian newsprint producers, to Jazz, culture, and 'Art Music' in 1950s America.

I would also like to take this opportunity to encourage you to visit our 'Abstracts' section, which now includes abstracts written by students taking part in the College of Biological Sciences Poster Day event.

A heartfelt thanks to all faculty involved in this issue's publication - our undergraduate experience couldn't have been the same without you. Additionally, I extend my gratitude to all contributors - your hard work and dedication will remain engraved in the history of research at our University.

Enjoy our fifth issue and we look forward to seeing you in the winter.

Sincerely,

Robert Berger

Editor in-Chief 